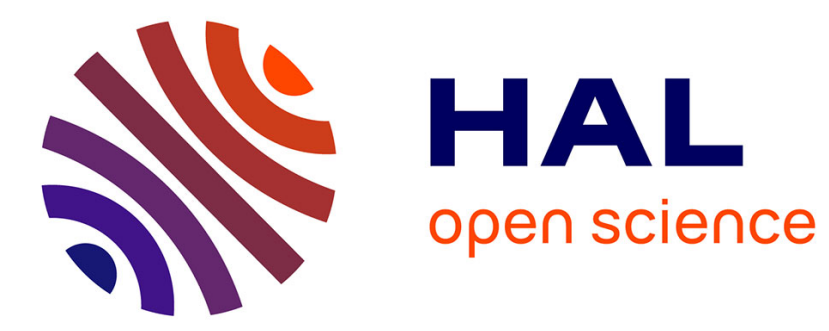

\title{
Knowledge Management, Value Chain Modelling and Simulation as Primary Tools for Mass Customization
}

\author{
Joanna Daaboul, Alain Bernard, Florent Laroche
}

\section{To cite this version:}

Joanna Daaboul, Alain Bernard, Florent Laroche. Knowledge Management, Value Chain Modelling and Simulation as Primary Tools for Mass Customization. International Conference on Concurrent Enterprising, Jun 2008, Leiben, Netherlands. pp.36. hal-00412085

\section{HAL Id: hal-00412085 \\ https://hal.science/hal-00412085}

Submitted on 31 Aug 2009

HAL is a multi-disciplinary open access archive for the deposit and dissemination of scientific research documents, whether they are published or not. The documents may come from teaching and research institutions in France or abroad, or from public or private research centers.
L'archive ouverte pluridisciplinaire HAL, est destinée au dépôt et à la diffusion de documents scientifiques de niveau recherche, publiés ou non, émanant des établissements d'enseignement et de recherche français ou étrangers, des laboratoires publics ou privés. 


\title{
Knowledge Management, Value Chain Modelling and Simulation as Primary Tools for Mass Customization
}

\author{
Joanna Daaboul, Alain Bernard, Florent Laroche \\ IRCCyN-ECN, Rue de la Noë 1, 44300 Nantes, France, \{firstname.name\}@irccyn.ec-nantes.fr
}

\begin{abstract}
Even though it is an attractive strategy, Mass customization (MC) is not feasible in all environments, and when it is, it presents many challenges to be dealt with [Aigbedo 2007 and Helms, et al. 2008]. Therefore, an extensive study on how to implement $\mathrm{MC}$ is needed before the actual implementation. Collaboration is a necessity in a $\mathrm{MC}$ environment, whether between the customer and the company, the company and its supply chain partners, or the different members of the company's value chain. Knowledge management is a tool that assures this collaboration by better capturing, storing, and reusing data. In addition deciding on whether to implement MC or not is not an easy task; simulation can be used as a decision support system by evaluating the company's performances. This paper presents Knowledge management, value chain modelling and simulation as tools for MC implementation, applied on the shoe industry under a European project named DOROTHY.
\end{abstract}

\section{Keywords}

Mass Customization, Knowledge Management, Value chain modelling, Simulation, Collaboration

\section{Introduction}

Even though it is an attractive strategy, Mass customization is not feasible in all environments, and when it is, it presents many challenges to be dealt with [Aigbedo 2007 and Helms, et al. 2008]. The two main challenges to mass customization are time and cost [Eastwood 1996]. Thus before implementing MC, the company should do an extensive analysis on the best way for MC implementation, on whether it is advantageous and profitable to apply it, on the cost of implementing it, and finally on its readiness for such a strategy.

In order to overcome the two main challenges created by MC it is necessary to optimize the product differentiation level, establishing a suitable trade-off between external variety versus internal complexity [Jiao, Tseng, 2004]. At the same, a strong coordination and collaboration between different players in the supply chain has to be assured [Dietrich, Kirn, Timm, 2006]. The use of Knowledge systems solves these two issues. Therefore knowledge management is valuable to $\mathrm{MC}$ by offering the base for knowledge creation and distribution. Hence leading to a strong collaboration whether with the customer or the suppliers; moreover, it provides the needed knowledge to be applied for problems such as optimizing external variety versus internal complexity [Helms, et al. 2008].

\section{Mass Customization and Knowledge Management}

Insufficient collaboration between the main agents involved in the customization process, mainly the customer, the company and the suppliers as well as failures in transmitting and translating customer's requirements to the design and production teams are major problems causing delay in product manufacturing and delivery [Dietrich, Timm, Kirn, 2006]. This will lead to increased cost, increased internal complexity, and reduced customer satisfaction. Therefore knowledge management (KM) is a main factor and tool for the success of a MC system [Frutos, Borenstein, 2004]. Knowledge management can be seen as a business process that identifies, collects, 
creates, organizes, stores, and distributes valuable knowledge in order to apply it to problems and use it to attain certain goals [Raman 2006]. It leads to the improvement of customer relationship management, supply chain management, and product development [Fahey, et al. 2001].

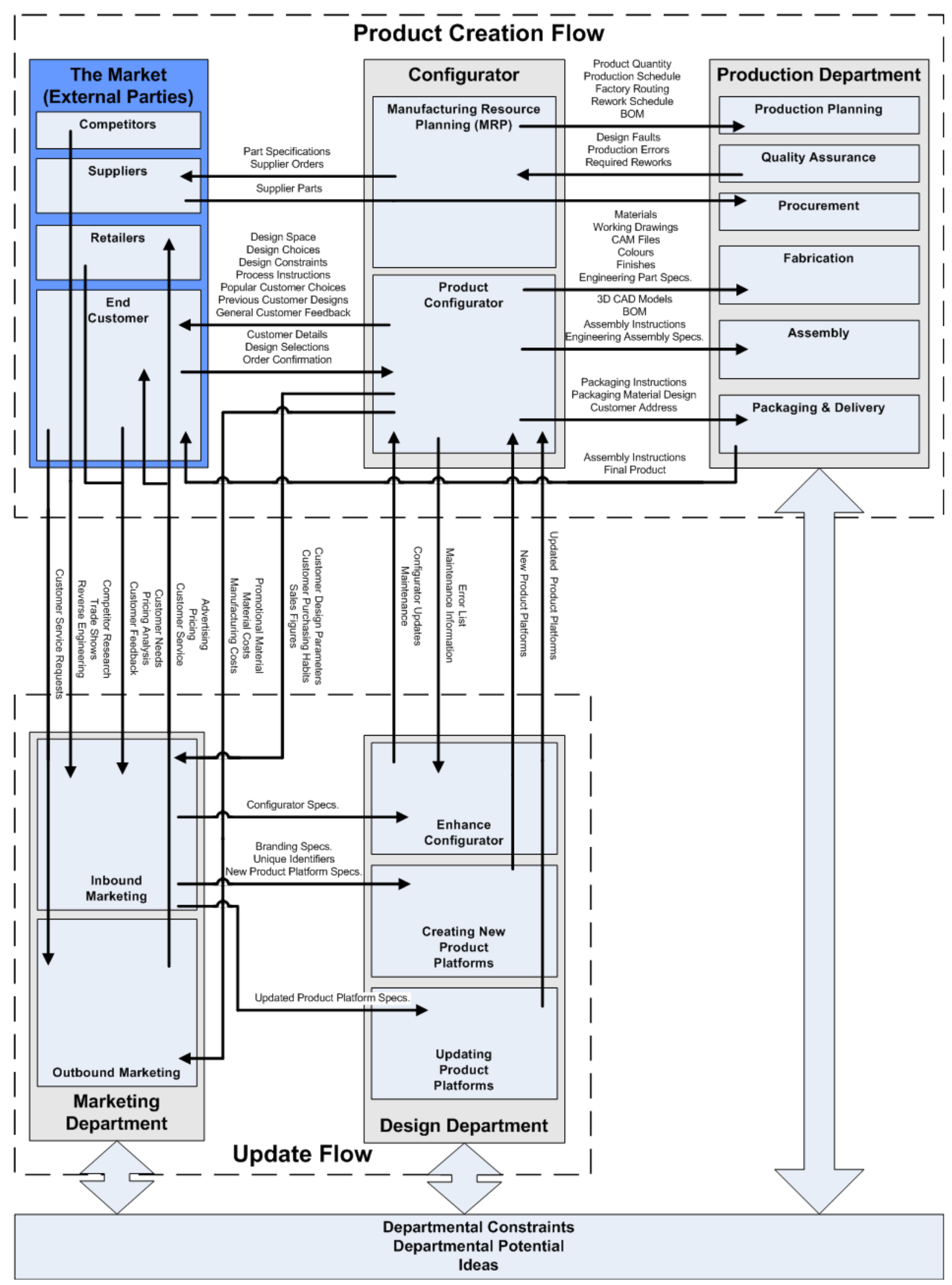

Figure 1: Design communication flow through a mass customisation firm [Cross, Seidel, R., Seidel, M. and Shahbazpour 2009] 
Knowledge management is necessary to a company for achieving innovation in products, processes, services, and organization. Also, it leads to reduction in costs of design, production, distribution, and others [Ammar-Khodja, Bernard 2008]. The literature presents many definitions for KM. From these definitions four main principles to be considered when managing knowledge are highlighted. These are that knowledge is connected and is applicable in new environments. That $\mathrm{KM}$ is an action or a catalyst, and its solutions depend on having a knowledge sharing culture [Ammar-Khodja, Bernard 2008]. Many aspects need to be considered when managing knowledge. First of all, Knowledge is used by different users at different times, and is transferred from a user to another knowing that not all users are considered by the same point of views. Secondly, the used software influences the modeling task since it offers certain views leading to information redundancy. Finally, the transformation of knowledge needs to be modeled too, because knowledge is not static [Labrousse, Bernard 2008]. In addition two flows of data need to be managed; the first one is the product creation flow which is the flow of customer requirements to all departments and suppliers in order to produce the customized product. The question here is what data is transferred to what department or which partner. The second one is the update flow which is the use of customer collected data for design of new and innovative products and for improving the marketing strategy, product platforms, design configurator and production processes [Cross, Seidel, R., Seidel, M., Shahbazpour 2009]. Those two flows are illustrated in figure 1.

\section{Mass Customization and Simulation}

After planning for the change induced by MC, the decision of implementing it remains hard to be made. Is it profitable? Is the increase in customer satisfaction and market share worth the effort and the complexity created by MC? Evaluation is needed at first for deciding on whether or not to implement MC. Secondly, it is used for company's progressive improvement and development. The basic method to do so is by evaluating the cost of implementing MC, nevertheless considering the cost at the only performance and evaluation indicator is not enough.

Wang [2008] argues that one way to evaluate mass customization is by agility evaluation of the manufacturing system, since the implementation of mass customization necessities the development of an agile-based manufacturing system. Yang and Li [2002] suggested the use of multi-grade fuzzy assessments of manufacturing agility of a mass customized product. They take into consideration the organization management agility, the products design agility, and the processing manufacture agility. Each of these factors is assessed separately, and then weights are associated to every factor. By multiplying every weight to its corresponding factor we get the utility evaluation of every factor. The mean of all individual factors' utility will be the utility of the entire manufacturing system. The disadvantage of this method is that the evaluation is based on experts' opinion, which is subjective.

Another agility evaluation method which is the use of 2-tuple fuzzy linguistic computing was presented by Wang [2008]. He considers five factors for evaluating the agility of mass customization system. These factors are the organization management agility, the product design agility, the processing manufacture agility, the partnership formation capability, and the integration of information system. A detailed description of the method is found in Wang [2008]. The problem is that agility evaluation doesn't help in deciding whether to implement MC or not, but it determines whether a company is ready or not for such a strategy.

The use of simulation as a tool for decision support by evaluation of the enterprise performances [Mauchand 2007] helps the company not only in deciding if it is ready or not for implementing $\mathrm{MC}$, but also in deciding whether it should or not implement it.

Dietrich et al. [2006] also use an agent-based system because it is a promising approach in computer-mediated supply webs. Agents' technology can be applied to identify existing 
limitations in today's manufacturing system and to overcome them proposing new solutions, as explained by Marik et al. [2002]. They presented the DAISY [Deliberate Agents for Intelligent Simulation SYstems] approach which is a framework for modeling, design, implementation, simulation and realization of an agent-based system for support of mass customization. Its purpose is guiding researchers through the analysis of the domain, design of processes, and implementation of an agent-base simulation system for a particular scenario. This approach is applied on a case study 'EwoMacs' which goals are analyzing logistic structures and developing an adaptable business model for mass customization in the field of custom-made shoes. DAISY consists of five steps. The first one is modeling the business process through a standard language and tool. The second step consists of transferring this model into a simulation model. Automatic synthesis of generic agent systems from simulation and business process models constitutes the third step, while the fourth step is to enhance the agent model through replacing agents by intelligent agents. Finally a detailed simulation using the multi-agent system is performed.

Our work will be based on the method developed by M. Mauchand [Mauchand 2007]. She used simulation as a decision support tool aiming on evaluating the performance of the enterprise. According to her the concepts related to performance are cost, quality, time and value. She used the FBS-PPRE (Function, Behavior, Structure- Process, Product, resource, External Effect) [Labrousse, Bernard, 2008] as a modeling method, and ABC (Activity Based Costing) as a cost estimation method.

The different steps of her approach are at first generating the different value creating activities and value chains that satisfies the customer's demand. Secondly the value chains are modeled. Then the different suggested alternatives are simulated. Finally the simulation results are analyzed using the AHP (Analytic Hierarchy Process) method that allows multi-criteria analysis. It is worth noting that her suggested simulation model is a multi-level model for one product only and the used simulation software was Arena. We will extend her developed model to fit for our MC scenarios.

\section{Case Study: DOROTHY}

DOROTHY is a medium size research project aiming at enhancing the competitiveness of the European shoe industry, by developing the necessary tools and methods to support a customer driven design and a multi-nation multi-site factory. DOROTHY' mission is to offer the possibility for a customer anywhere in the world to co-design his/her shoes that will be manufactured in a multi-site multi-nation factory and delivered to him/her. In order to achieve this mission, DOROTHY tackles three main scientific and technological objectives:

- Cluster 1: Design tools for customer driven and customer fit shoe

- Cluster 2: Design tools for advanced industrial engineering of multi-site and multi-nation production systems and factories, based on the customer driven shoe

- Cluster 3: New business models for the multi-nation multi-site shoes

The results of DOROTHY shall be extended and generalized in order to be applied also in other industries.

Both knowledge management and simulation will be main tools in achieving DOROTHY' objectives.

\subsection{Level of Customization}

One of the main decisions concerns the level of offered customization or more precisely the point of customer involvement in the value chain. Will the customer co-design the product? Or would he simply add some features to it, or choose among suggested options? The level of customization determines the internal complexity to be dealt with. Thus two questions need to be 
tackled, what is the level of customization and the degree of variety offered to the customer. It stands necessary to separate between mass customization and pure customization because some compromise, limitations, and constraints are unavoidable if mass characteristics (responsiveness, efficiency, high throughput with high quality) are to be attained and if high prices are to be avoided [MacCarthy, et al. 2002]. Mass customizers can be classified based on two characteristics: the point in the production cycle of customer involvement and the type of product modularity [Duray, et al. 2000]. There exists two ways of deciding on the level of customization or customization strategy, the first one is by simply deciding on the wanted level of customization and then do all the necessary studies and planning to check if it is applicable. The second one is by analyzing the cost of induced change and the applicability of MC to get the optimal level of offered customization. In DOROTHY, we tackle the problem following the first way. Different levels of customization, represented by various scenarios, will be analysed. These scenarios are depicted by the project industrial partners' decision makers on the basis of their experience and feelings. The proposed scenarios vary from a low level of customization in which just the best fitting shoe is chosen for the customer, to a high level of customization in which the customer is able to choose the material, colour, components of his/her shoe which is produced based on his/her feet dimensions. The following are two of the suggested scenarios that reflect the expectations of one of the project industrial partners.

In scenario A, the customer's feet are measured and his motion is analysed. Then the customer customizes his shoe colour/components on a screen. Finally the customer chooses to take the non-customized shoe or the customized one that costs A\% more and will be delivered in a lead time of X days to his home or his favourite shop. Shoes would be stored in the central warehouses and pairs of shoes would be collected and delivered to the shop depending on specific customer needs and feet sizes.

In scenario B, parts of the shoes are produced in current factory, for instance sole making and upper making in different sizes, shapes and colours (without any assembly). Parts are delivered to warehouses and the final assembly is done after customer's order in a mini factory which takes place near the warehouse according to customer needs and feet sizes. After measuring the customer's feet and analysing his motion. He/she customizes his shoe colour/components on a screen. Finally the customer chooses to take the non-customized shoe or the customized one that costs $\mathrm{B} \%$ more and will be delivered in a lead time of $\mathrm{Y}$ days to his home or his favourite shop.

\subsection{Knowledge management}

For every scenario we need to identify, the data flow, the critical data, what information is transferred to machines and computers, what data is to be sent to which partner or member of the value chain and where we can gain time, efficiency, and value. And since the level of customization and its type differs from a scenario to another the previously stated factors will probably vary from one scenario to another. The update flow will basically be the same for all scenarios, but the product creation flow is changing from one scenario to another. The complexity of this flow increases with the increasing level of customization. For example, in scenario B the mini factory is added to the value chain partners, which leads to an increase in the complexity of data flow. Modelling the data flow for every scenario is possible only after the final definition of the scenarios.

\subsection{Value chain modeling}

\subsubsection{Determining Performance and value indicators}

The combination of the three performance indicators cost, quality and time results in the value assessment [Chen, Huang, 2006]. Nevertheless many other criteria can be added to this combination, such as customer perception, and environment respect. But in this model only measurable and observable data are taken into account. The value of the product to the client can increase or decrease since it depends on the cost, quality and delay time of the product which can evolve [Mauchand, et al. 2007]. 
As the data flow, the performance indicators might vary from a scenario to another. Some performance indicators might be of higher importance to some scenarios and might be calculated or estimated differently for every scenario. For example in the lowest level of customization scenario, the time to deliver the customized shoe to the customer which is a main performance indicator is based on the time of delivering the best fitting shoe from the warehouse to the shop and depends on the availability of this shoe in the warehouse. On the other hand in the high level customization scenario, the time to deliver the customized shoe depends on the availability of the material in the factory, plus the assembly time of the customized shoe and plus its transportation time to the shop.

\subsubsection{Modeling}

The general reference system that will be shared between all the actors of the value chain is composed of two major models the product model and the process model. Nevertheless the two models are highly connected [Labrousse and Bernard, 2008]. The literature presents many approaches to model the enterprises objects including process object, product object, resource object, and external effect object. Among these are the IDEF0, GRAI, FBS, MOKA, etc... All these approaches do not tend to be universal, and are restricted to the product view. Hence, Labrousse and Bernard proposed a generic model: the FBS-PPRE Model. This model offers advances in three areas: the completeness of the modeling, the management of the dynamic of the objects, the conceptual unification. Completeness is assured by the wider view that the model offers. Every object influencing the enterprise processes which are defined as "temporal, spatial and hierarchical organization of activities using resources to make products (output)" [Labrousse, Bernard, 2008] is modeled. These objects are modeled based on their role of product, resource, or external effect with the same views: the functional, the behavioral and the structural view [Labrousse, Bernard, 2008].

\subsection{Simulation}

The value chain of every scenario will be simulated, allowing the measurement of the predefined performance indicators. Then value can be assessed. This will support the enterprise managerial level in deciding on whether to implement MC or not and on the applicability of the desired level of customization. Moreover simulating the scenarios' value chains will allow their manipulation in order to improve their design aiming at better performances and increased attained value. The simulation model shall provide multi-levels and different views of the value chain. Basically, Arena 7.0 will be the used software for simulation.

\section{Conclusion and Outlook}

Knowledge management is one of the main enablers of mass customization; it is a necessary tool to assure collaboration between the different partners of the value chain and to reduce the induced internal complexity due to product differentiation. In addition, value chain modelling and simulation can be used as a decision support tool for deciding on whether to apply Mass Customization and on its level.

In the future the data flow between all partners of the value chain will be modelled. Also after determining performance indicators and their estimations, the value chains of the suggested scenarios for customer driven shoe design and production under DOROTHY will be modelled, and simulated to validate them and to study their applicability.

\section{Acknowledgement}

The European Commission through DOROTHY Project: Design of customer driven shoes and multi-site factory (No. FP7-NMP-2007-3.3-1), has partly funded this work. The authors would like to acknowledge the Commission for their support. We also wish to acknowledge our gratitude and appreciation to all the DOROTHY project partners for their contribution during the development of various ideas and concepts presented in this paper. 


\section{References}

Aigbedo, H. (2007) An assessment of the effect of mass customization on suppliers, inventory levels in a JIT supply chain. European Journal of Operational Research, Vol. 181 No.2, pp. 704-715.

Ammar-Khodja, S. and Bernard, A. (2008) An overview on knowledge management. In: Bernard, A. and Tichkiewitch, S. (Eds): Methods and tools for effective knowledge life-cycle-management. Springer 2008, pp. 3-21.

Chen, KS. and Huang, ML. (2006) Performance measurement for a manufacturing system based on quality, cost and time. International Journal of Production Research, Vol. 44, No. 11, pp. 2221-2243.

Coss, R., Seidel, R., Seidel, M. and Shahbazpour, M. (2009) Design communication for mass customization. International Journal of Mass Customization, Vol. 3, No. 2, pp.146-164.

Dietrich, A.J., Kirn, S. and Timm, I.J. (2006) Implications of mass customization on business information systems. International Journal of Mass Customization, Vol. 1, Nos. 2/3, pp.218-236.

DOROTHY: Design of customer driven shoes and multi-site factory. https://web.ttsnetwork.net/dorothy/pages/index.jsp, accessed 3.3.2009.

Duray R. (2000) Mass customization origins: mass or custom manufacturing?. International Journal of Operations and Production Management, Vol. 22, No.3, pp. 314-28.

Eastwood, M.A. (1996) Implementing mass customization. Computers in Industry, Vol. 30, pp. 171-174.

Fahey, L., Srivastava, R., Sharon, J.S. and Smith, D.E. (2001) Linking e-business and operating processes: the role of knowledge management . IBM Systems Journal, Vol. 40, No. 4, pp. 889-907.

Frutos, J.D. and Borenstein, D. (2004) A framework to support customer-company interaction in mass customization environments. Computers in Industry, Vol. 54, pp.115-135.

Helms, M.M., Ahmadi, M., Jih, W.J.K. and Ettkin, L.P. (2008) Technologies in support of mass customization strategy: exploring the linkages between e-commerce \& knowledge management. Computers in Industry, Vol. 59 , pp.351-363

Jiao, J. and Tseng, M.M. (2004) Customizability analysis in design for mass customization. Computer-Aided Design, Vol. 36, pp. 745-757.

Labrousse, M. And Bernard, A. (2008) FBS-PPRE, an enterprise knowledge lifecycle model. In: Bernard, A. and Tichkiewitch, S. (Eds): Methods and tools for effective knowledge life-cycle-management. Springer 2008, pp. 285-305.

MacCarthy, B.L., Brabazon, P.G. and Bramham, J. (2002) Key value attributes in mass customization, In: Rautenstrauch, C., Seelmann-Eggbert, R., Turowski, K. (Eds.), Moving into Mass Customization: Information Systems and Management Principles. Springer, Berlin, pp. 71-89

Marík, V., Camarinha-Matos, L.M. and Afsarmanesh, H. (2002) Knowledge and technology integration in products and services. Proceedings Balancing Knowledge and Technology in Product and Service Life Cycle (BASYS '02), Cancun, Mexico.

Mauchand, M. (2007) Modelisation pour la simulation de chaines de production de valeur en entreprise industrielle comme outil D'aide a la decision en phase de conception / industrialisation. $\mathrm{PhD}$. Thesis Ecole Centrale Nantes.

Mauchand, M., Bernard, A., Siadat, A. And Perry, N. (2007) Enterprise processes performance analysis based on value chain modelling and simulation. CARV

Raman, M. (2006) Wiki technology as a free collaborative tool within an organizational setting. Information Systems Management, Vol. 23, No. 4, pp. 59-67.

Wang, W.-P. (2008) Toward developing agility evaluation of mass customization systems using 2-tuple linguistic computing. Expert Systems with Applications.

Yang, S.L. and Li, T.F. (2002) Agility evaluation of mass customization product manufacturing. Journal of Materials Processing Technology, Vol. 129, pp. 640-644. 